\title{
Effect of Welding Conditions of Spot Welded Zone on the Tensile Strength about Aluminum Alloy (A6061)
}

\author{
Keiji Sonoya ${ }^{1, *}$, Kosuke Fukui ${ }^{2}$, Motohisa Suzuki ${ }^{2}$ \\ ${ }^{1}$ Department of Mechanical Engineering, University of Yamanashi, Japan \\ ${ }^{2}$ OBARA Corporation, Japan
}

Copyright (C) 2016 by authors, all rights reserved. Authors agree that this article remains permanently open access under the terms of the Creative Commons Attribution License 4.0 International License

\begin{abstract}
It is considered to be available in reducing the weight of automobiles that the aluminum alloy is applied to manufacture them. The spot welding of aluminum alloys is difficult because of high welding current and small electrical resistance. It is necessary to clarify the relation between the nugget formation and the welding conditions. In this study, the relation between the spot welding conditions and the nugget form was investigated, and the joint strength and the fracture mode were investigated. As a result, the nugget area and micro cracks in the HAZ were increased with increase of the welding current. It is found that in case of aluminum alloys the formation of micro cracks was a main factor of reduction of maximum tensile load of the welded zone.
\end{abstract}

Keywords Aluminum Alloy, Spot Welding, Welding Current, Nugget, HAZ, Micro Crack, Maximum Tensile Load

\section{Introduction}

Recently, the reduction of $\mathrm{CO}_{2}$ emissions from automobiles has become an important issue from the viewpoint of global environmental conservation. Also, reducing the weight of automobiles is essential for reducing environmental impact and improving the kinematic performance of automobiles. There are several methods of reducing the weight of automobiles. One effective measure is considered to be the replacement of steel body panels with aluminum-alloy body panels. ${ }^{1)}$

There are several methods of joining body panels of automobiles, such as spot welding, self-piercing riveting, ${ }^{2)}$ and friction stir welding. ${ }^{3)}$ Recently, spot welding has been frequently used because of its high productivity and low cost. During spot welding, sheet pieces to be welded are sandwiched between electrodes, across which voltage is applied to induce a current, generate Joule heat by electric resistance, and weld the interface between the sheet pieces by melting. Spot welding is appropriate for materials with a high electric resistance, such as steels; however, it requires approximately twice as much current in the case of materials with a low electric resistance, such as aluminum alloys. Therefore, a dedicated system for spot welding of aluminum alloys that can bear a high-capacitance power source and high current is required. In some cases, increasing the size of welding machines and the installation or expansion of the plant's power-receiving equipment are required. ${ }^{4)}$

Therefore, the development of a new spot-welding machine for aluminum alloys that fits the production method of automobiles and can reduce the spot-welding current is a challenge for realizing aluminum-alloy automobile body panels. To this end, the relationship among the spot-welding conditions for aluminum alloys, the state of the spot-welded zone, and welding strength should be clarified. In this study, a 6000-series aluminum alloy that is frequently used for automobile body panels was targeted. We examined the relationships (1) between spot-welding conditions (welding current, electrode force, and welding time) and the shape of nuggets and (2) between the shape of nuggets and the tensile load at the spot-welded zone obtained during the cross-tensile test, and compared the results with those of the spot-welded zone of steels.

\section{Experimental Method}

\subsection{Materials}

Aluminum alloy A6061-T4, a material for automobile body panels, was used in the experiment. Table 1 summarizes the chemical composition of A6061. The shape and dimensions of the specimen (thickness, $1.0 \mathrm{~mm}$ ) used in spot welding are shown in Fig. 1. Before spot welding, the specimen was cleaned with alkali and acid to remove oxide film. Table 2 summarizes the chemical composition of mild steel (thickness, $1.0 \mathrm{~mm}$ ) used for comparison. 
Table 1. Chemical compositions of A6061 (mass\%)

\begin{tabular}{|c|c|c|c|c|c|c|c|}
\hline $\mathrm{Si}$ & $\mathrm{Fe}$ & $\mathrm{Cu}$ & $\mathrm{Mn}$ & $\mathrm{Mg}$ & $\mathrm{Cr}$ & $\mathrm{Zn}$ & $\mathrm{Ti}+\mathrm{Zr}$ \\
\hline 0.62 & 0.70 & 0.27 & 0.15 & 0.98 & 0.16 & 0.25 & 0.15 \\
\hline
\end{tabular}
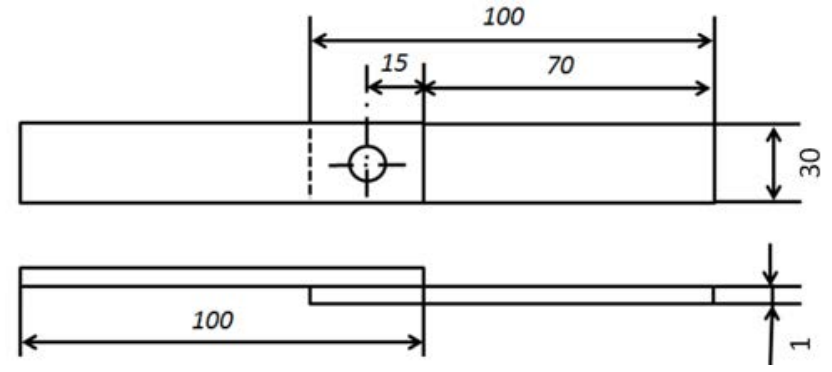

Figure 1. Configuration of the welding test piece

Table 2. Chemical compositions of mild steel (mass\%)

\begin{tabular}{|c|c|c|c|}
\hline C & Mn & P & S \\
\hline 0.15 & 0.60 & 0.01 & 0.02 \\
\hline
\end{tabular}

\subsection{Experimental Method}

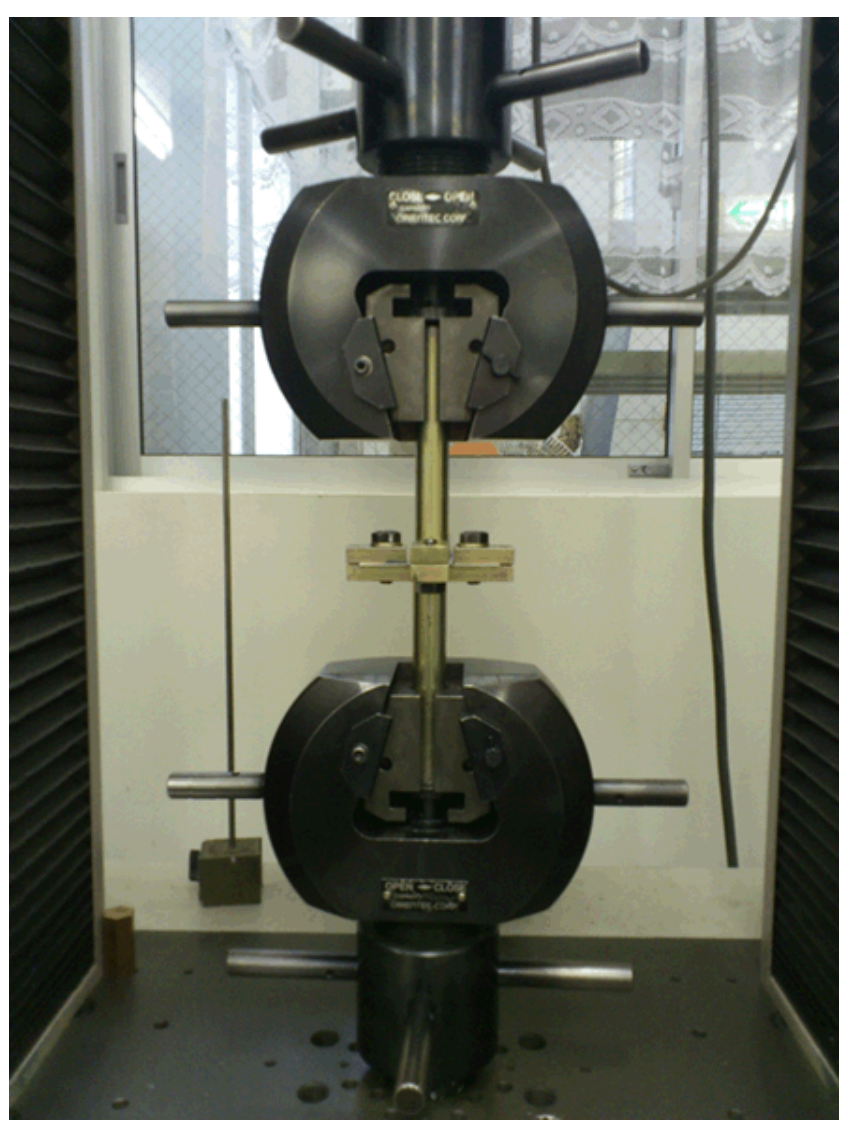

Figure 2. Appearance of cross tensile test machine

The shape of nuggets obtained under various welding conditions was observed. In addition, the tensile load at the spot-welded zone was measured by the cross-tensile test. As a spot-welding machine, a servo-controlled spot gun (SRTC-10731 rev) equipped with a DC inverter transformer (Obara Corporation) was used. The spot gun
(SRTC-10569KAI) was a C-type servo robot gun and its maximum electrode force was $5.88 \mathrm{kN}$. The specifications of the DC inverter transformer (ITSG85R-600-180C) were as follows: rated capacity, $85 \mathrm{kVA}$; primary voltage, single phase $600 \mathrm{~V}$; secondary voltage, $13.6 \mathrm{~V}$; frequency, $1.8 \mathrm{kHz}$. The electrode was of the $\mathrm{R}$ type [nominal diameter $(D), 16$ $\mathrm{mm}$; tip radius of curvature $(R), 40 \mathrm{~mm}]$. The inside of the electrode tip was cooled by flowing water to prevent overheating of the electrode. Before spot welding, trial welding was repeated 20 times for new electrodes. The cross-tensile test was carried out using the electrohydraulic servo-type tensile test machine (RTC-2430A) shown in Fig. 2 at a tensile speed of $10 \mathrm{~mm} / \mathrm{min}$. Mild steel specimens were used for comparison. Figure 3 shows the shape of a specimen used in the cross-tensile test.

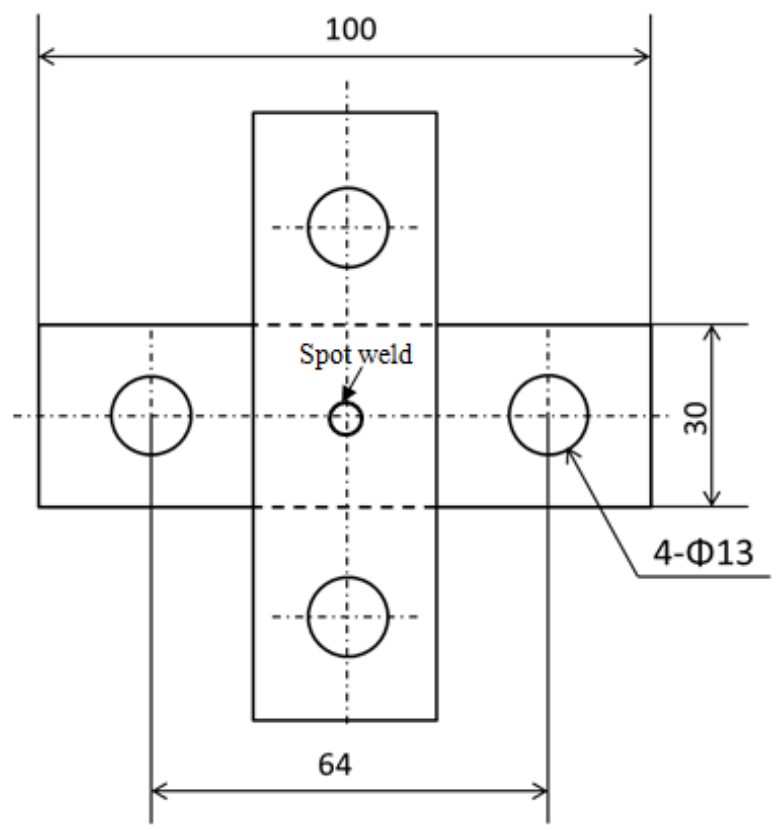

Figure 3. Configuration of cross tensile test piece

Table 3. Spot welding conditions for A6061

\begin{tabular}{|c|c|c|}
\hline Welding current (kA) & Electrode force $(\mathrm{kN})$ & Welding time (cycles) \\
\hline 15 & \multirow{8}{*}{4} & \multirow{12}{*}{10} \\
\hline 16 & & \\
\hline 17 & & \\
\hline 18 & & \\
\hline 19 & & \\
\hline 20 & & \\
\hline 21 & & \\
\hline 23 & & \\
\hline \multirow{8}{*}{22} & 2 & \\
\hline & 3 & \\
\hline & 5 & \\
\hline & 6 & \\
\hline & \multirow{4}{*}{4} & 5 \\
\hline & & 7 \\
\hline & & 10 \\
\hline & & 15 \\
\hline
\end{tabular}


Table 3 summarizes the spot-welding conditions for the observation of the shape of nuggets. On the basis of the results of previous studies, base welding current, welding time, and electrode force were set at $22 \mathrm{kA}, 10$ cycles, and 4 $\mathrm{kN}$, respectively. The actual welding current, welding time, and electrode force were varied in the ranges of 15-23 kA, 5-15 cycles ( 1 cycle $=0.02 \mathrm{~s}$ ), and 2-6 kN, respectively, and spot welding was repeated ten times under one combination of the above parameters. The microstructural observation of the cross section of specimens after spot welding was carried out to measure the nugget area and observe their structure including microfissures. To etch aluminum alloys, $10 \%$ $\mathrm{NaOH}$ solution was used. Nugget diameter was determined as the average of ten measurements obtained under the same spot-welding conditions.

Table 4. Spot welding conditions of A6061 for cross tensile test

\begin{tabular}{|c|c|c|}
\hline Welding current (kA) & Electrode force $(\mathrm{kN})$ & Welding time (cycles) \\
\hline 15 & \multirow{9}{*}{4} & \multirow{9}{*}{10} \\
\hline 16 & & \\
\hline 17 & & \\
\hline 18 & & \\
\hline 19 & & \\
\hline 20 & & \\
\hline 21 & & \\
\hline 22 & & \\
\hline 23 & & \\
\hline
\end{tabular}

Table 5. Spot welding conditions of mild steel for cross tensile test

\begin{tabular}{|c|c|c|}
\hline Welding current $(\mathrm{kA})$ & Electrode force $(\mathrm{kN})$ & Welding time (cycles) \\
\hline 5 & & \\
\cline { 1 - 1 } 6 & & \\
\cline { 1 - 1 } 7 & & \multirow{2}{*}{10} \\
\cline { 1 - 1 } 8 & & \\
\cline { 1 - 1 } 9 & & \\
\cline { 1 - 1 } 10 & & \\
\cline { 1 - 1 } 11 & & \\
\hline 12 & & \\
\hline
\end{tabular}

Tables 4 and 5 summarize the spot-welding conditions for aluminum alloy and mild steel specimens, respectively. The cross-tensile test was carried out ten times and the average of the ten maximum tensile loads was used as the tensile load of the spot-welded zone. After the cross-tensile test, the fracture state (e.g., the fracture path) and welding diameter at the spot-welded zone were examined. The tensile fracture surface was also examined by scanning electron microscopy (SEM). The welding diameter was measured by visual observation of the specimens obtained after the cross-tensile test, and the nugget area was calculated from the results of the microstructural observation of the cross section using image processing software (ImageJ). From the results of visual, microstructural, and SEM observations, we examined the growth of nuggets under different spot-welding conditions, the generation of welding defects, and the effect of the microstructural state on the tensile load at the spot-welded zone.

\section{Results}

\subsection{Relationship between Spot-welding Conditions and Nugget Area}

Figures 4-6 show the relationships of nugget area with welding current, welding time, and electrode force, respectively.

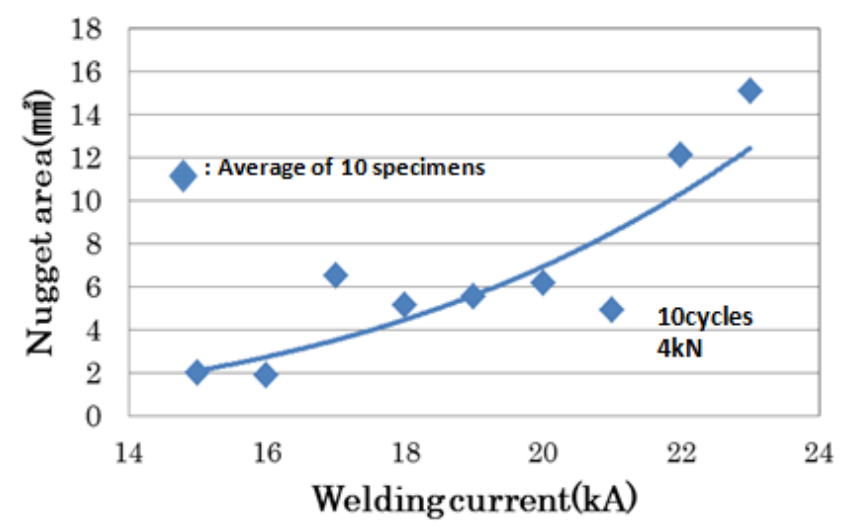

Figure 4. Relation between welding current and nugget area

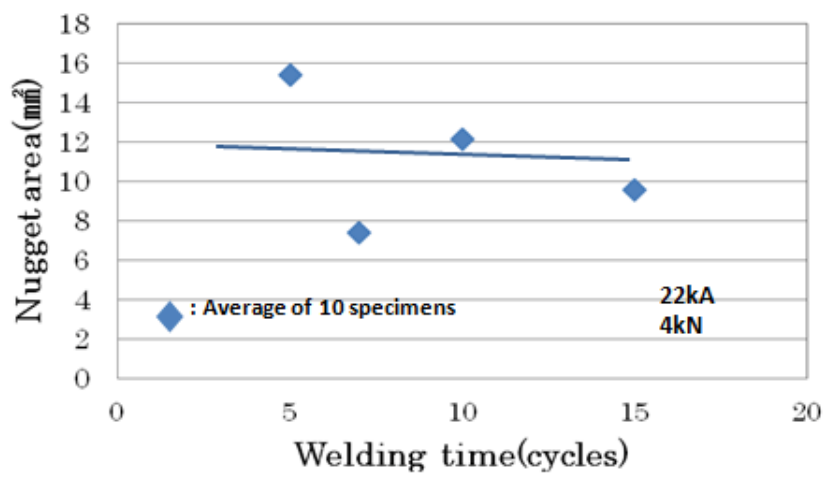

Figure 5. Relation between welding time and nugget area

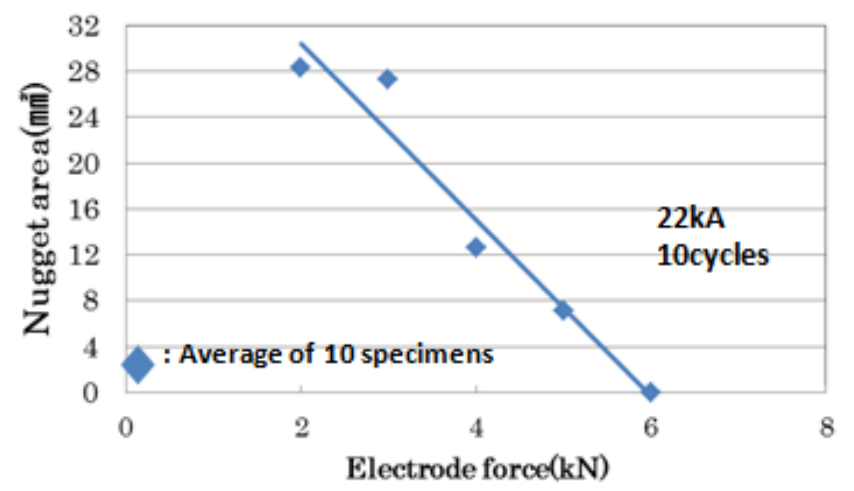

Figure 6. Relation between electrode force and nugget area

As shown in Fig. 4, when welding current increases, the nugget area increases. This is because the amount of heat 
generated increases with welding current, leading to increases in the amount of melted aluminum alloy and the nugget area.

As shown in Fig. 5, with increasing welding time, the nugget area almost changes. This finding indicates that the nuggets of aluminum alloy were formed within a short period and the formation of nuggets did not proceed further with continued flow of welding current. ${ }^{5)}$ As shown in Fig. 6, with increasing electrode force, the nugget area decreases. No nugget was observed at an electrode force of $6 \mathrm{kN}$. Heat is generated by contact resistance at the electrode/aluminum alloy sheet and aluminum alloy sheet/aluminum alloy sheet interfaces and dielectric breakdown. Therefore, when the electrode force is small, the heat generated by contact resistance is considered to be large. For spot welding, the initial electric conduction diameter (electric conduction area) significantly affects the temperature increase at the welded zone and the formation rate of nuggets decreases with increasing electric conduction diameter. ${ }^{6)}$ The indentation at the welded zone of aluminum alloy was relatively deep because the proof stress of aluminum alloy at high temperatures is extremely low compared with that of mild steel. In the nuggets, defects, such as blowholes and hot cracks, were observed. Hot cracks easily develop in aluminum alloys because of a high degree of solidification contraction due to a wide solid-liquid coexistence temperature range where aluminum alloy is semimolten. Namely, A6061 is considered to have a relatively high crack sensitivity. ${ }^{7,8)}$

\subsection{Results of Macrostructural and Microstructural Cross-sectional Observation}

Figure 7 shows macrostructures of the cross sections of welded zones of aluminum alloy obtained by spot welding at welding currents of 15,18 , and $23 \mathrm{kA}$. With increasing welding current, both nugget diameter and thickness increase. At the center of the nugget in the spot-welded zone obtained at the welding current of $23 \mathrm{kA}$, blowholes are observed. The width of the heat-affected zones (HAZs) tends to be small under any welding current.

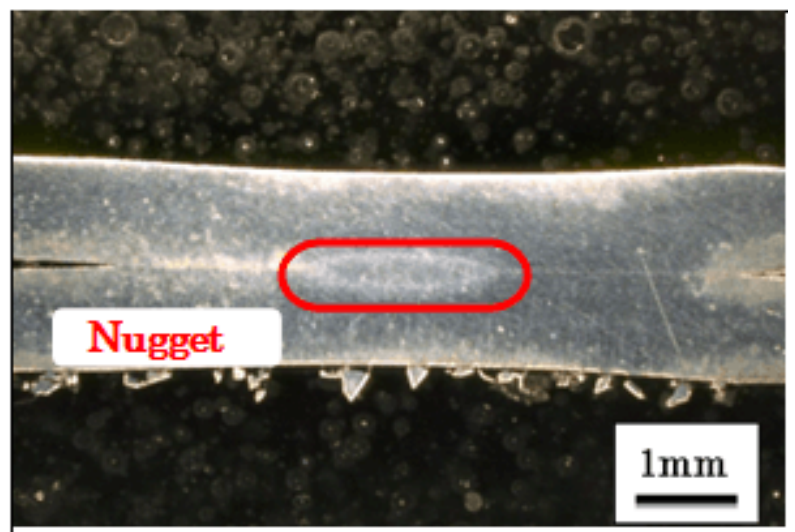

(a)Welding current : 15kA

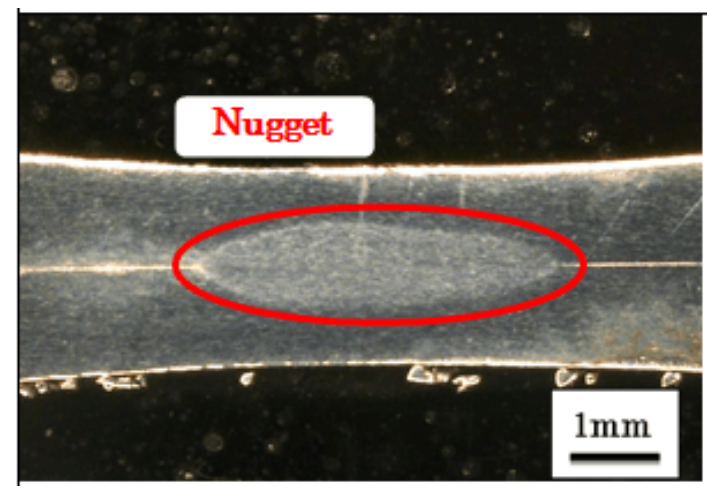

(b)Welding current : 18kA

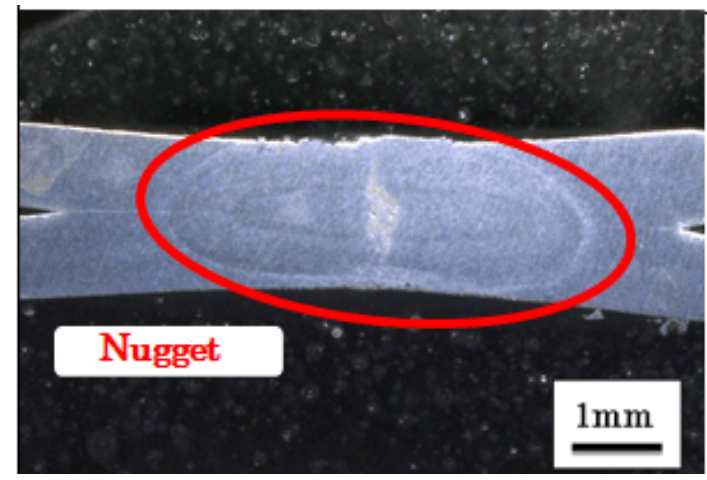

(c)Welding current : 23kA

Figure 7. Macro structure in spot welded zone of A6061 with the change of welding current

Figure 8 shows microstructures of HAZs of aluminum alloy obtained by spot welding at welding currents of 15,19 , and $23 \mathrm{kA}$. With increasing welding current, the number of cracks tends to increase. As shown in Fig. 9, eutectic melting and microfissures coexist along grain boundaries in HAZs. ${ }^{9)}$ The eutectic melting and microfissures in HAZs are minute and discontinuous; they are microscopically detected but macroscopically undistinguishable. ${ }^{10)}$ The amount of eutectic melting and the number and width of microfissures increase with increasing welding current.

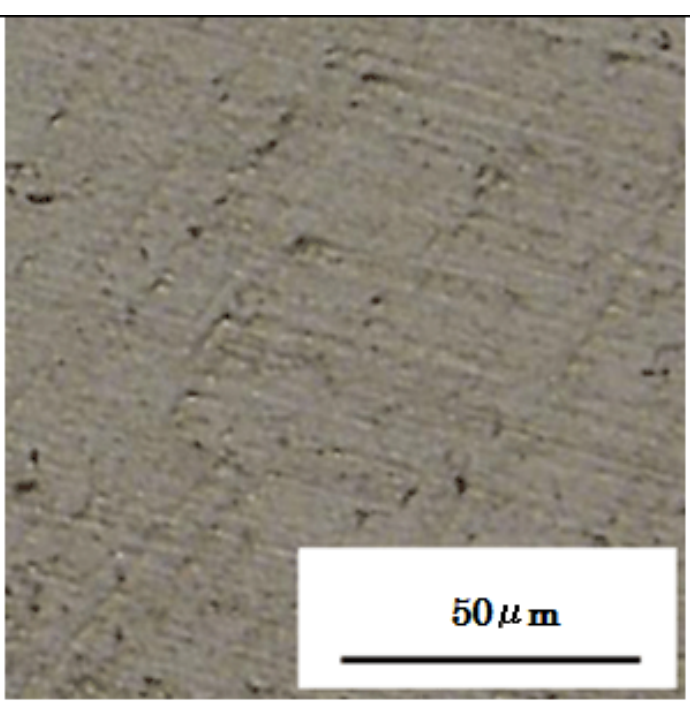

(a) Welding current : 15kA 


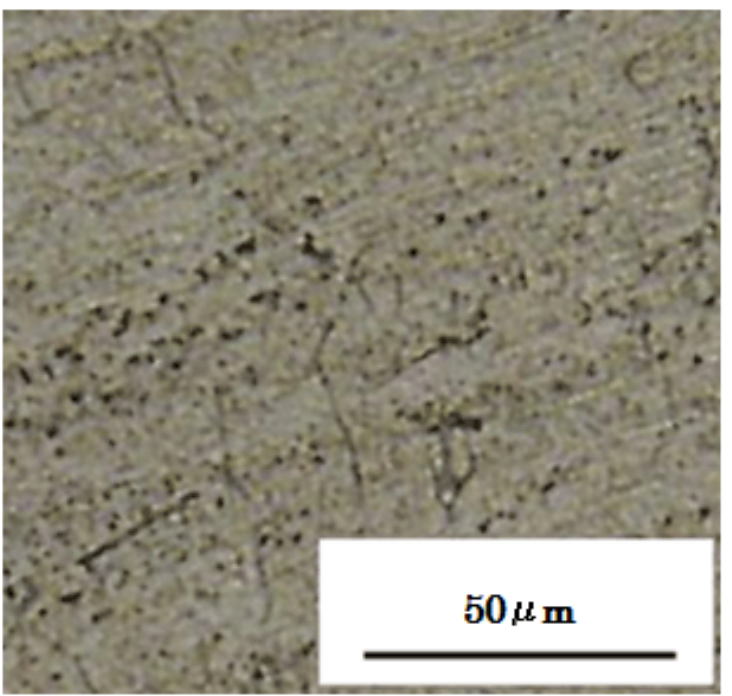

(b) Welding current : 19kA

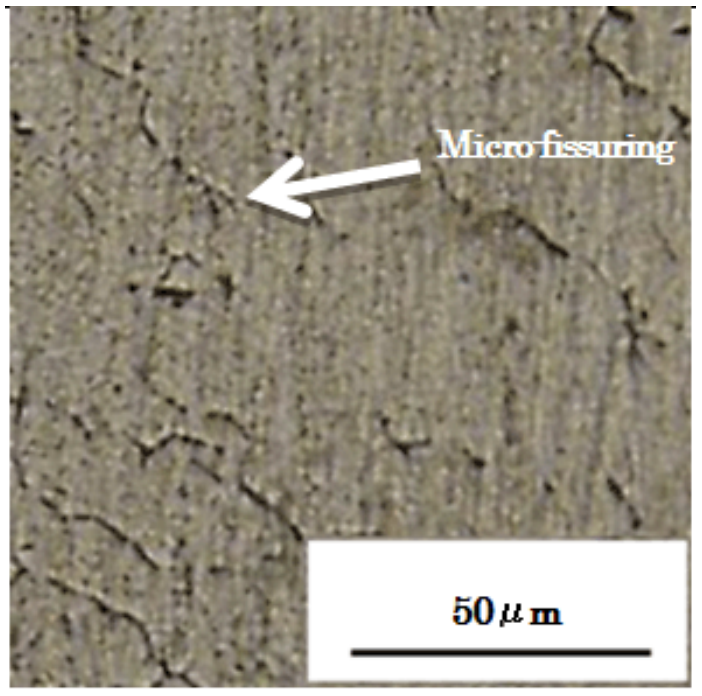

(c) Welding current : 23kA

Figure 8. Changes in the HAZ micro-fissuring with increase in welding current of A6061

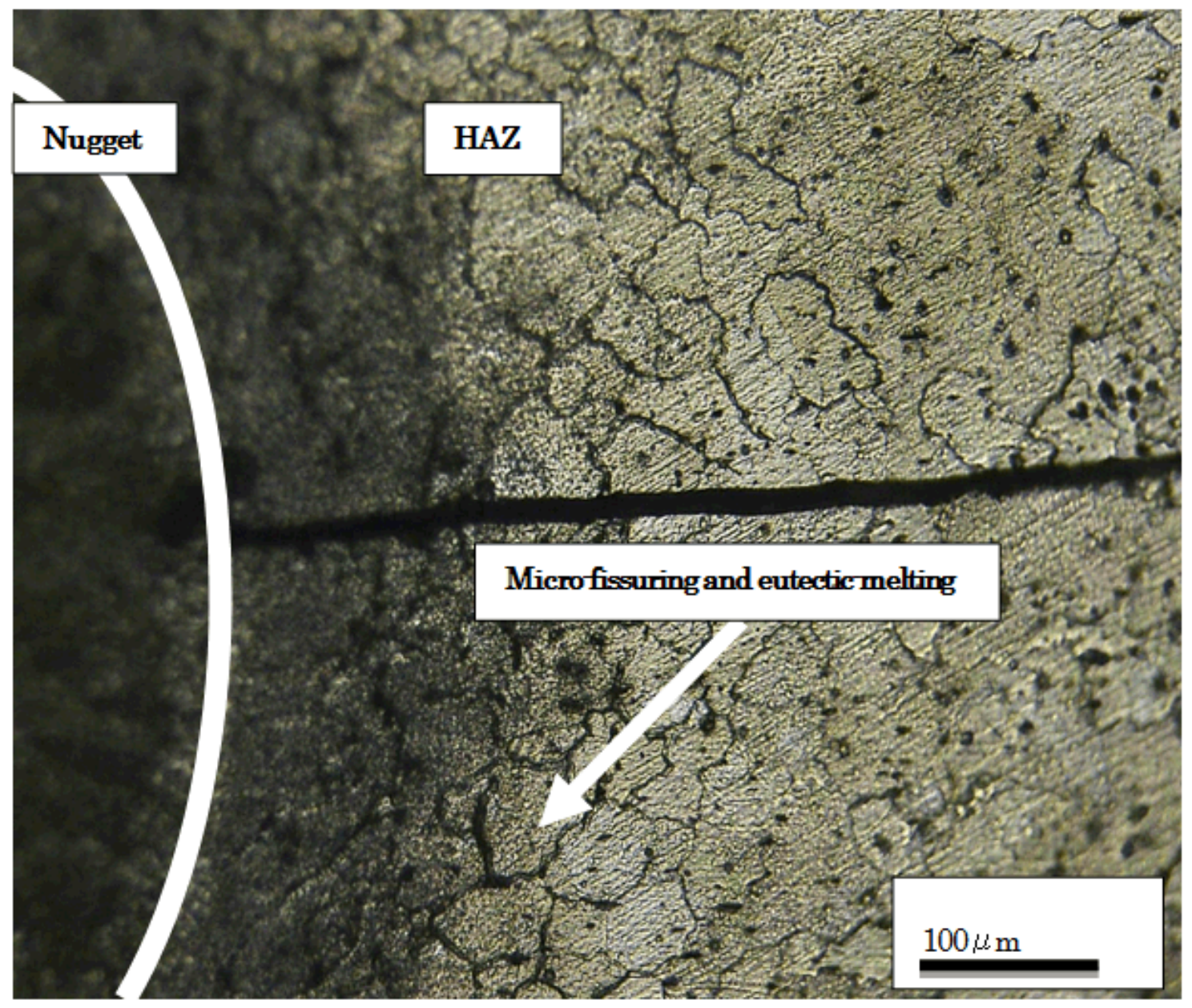

Welding current : 22kA

Figure 9. Micro-fissuring and eutectic-melting observed in the HAZ of spot welded zone for A6061 


\subsection{Results of Cross-tensile Test}

Figure 10 shows the relationship between welding current and maximum tensile load for the spot-welded zones obtained after the cross-tensile test.

Maximum tensile load increases with increasing welding current up to $17 \mathrm{kA}$. However, the maximum tensile load becomes almost constant $(\sim 0.9 \mathrm{kN})$ at a welding current of $17 \mathrm{kA}$ or higher. Under the spot-welding conditions examined in this study, no sputtering was observed for aluminum alloy, unlike the case of mild steel. Figure 11 shows the relationship between welding current and welding diameter measured using a vernier caliper, as well as that between welding current and nugget diameter. Welding diameter and nugget diameter increase with increasing welding current. Welding diameter is equivalent to nugget diameter at low welding currents; however, welding diameter tends to be smaller than nugget diameter at high welding currents.

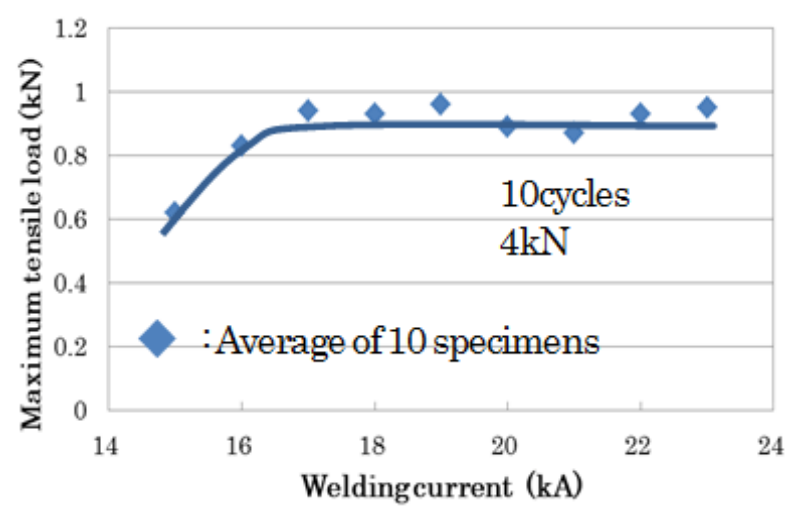

Figure 10. Relation between welding current and maximum tensile load in cross tensile test of A6061

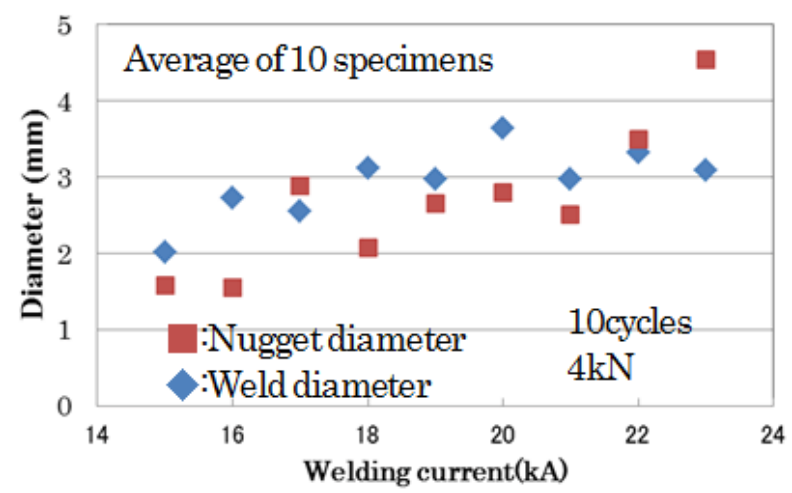

Figure 11. Relation between welding current and Nugget diameter, weld diameter in the spot welded zone for A6061

\subsection{Fracture State of Spot-welded Zone Obtained after Cross-tensile Test}

Figure 12 shows macrostructures of the cross section of the fractured spot-welded zone obtained after the cross-tensile test of aluminum alloy at different welding currents.

The fracture state depends on welding current. At a welding current of $15 \mathrm{kA}$, the fracture is observed only inside the nugget. At a welding current of $18 \mathrm{kA}$, the fracture extends along the nugget. At a welding current of $23 \mathrm{kA}$, fracture is generated in the HAZ. In addition, at welding currents of 18 and $23 \mathrm{kA}$, significant defects, such as hot cracks and blowholes, are observed inside the nugget.

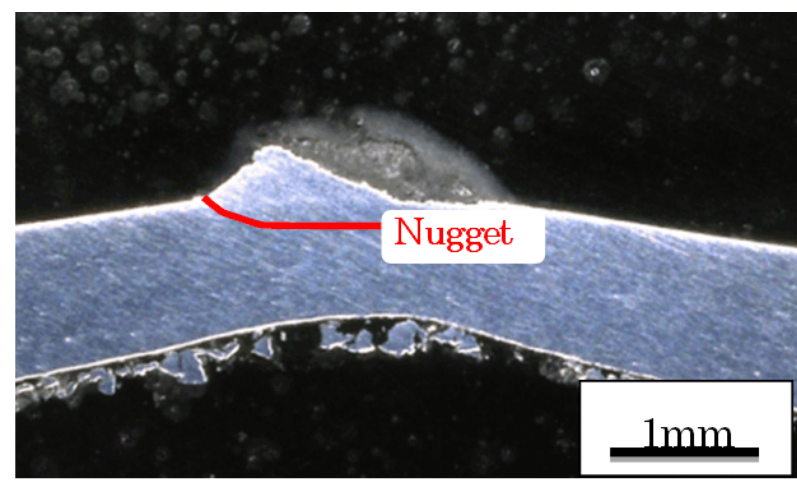

(a) Welding current : 15kA

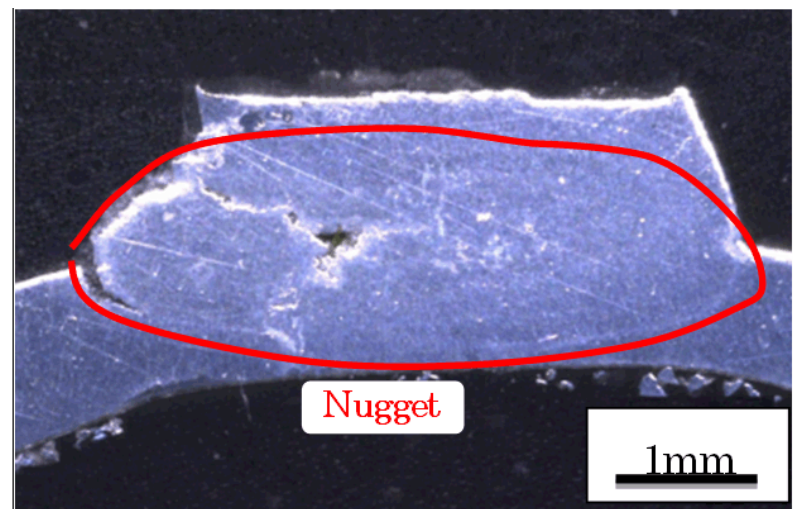

(b) Welding current : 18kA

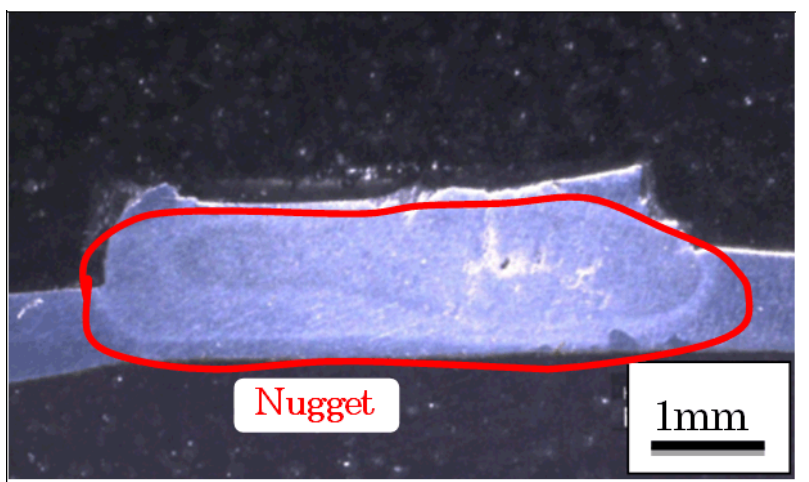

(c) Welding current : 23kA

Figure 12. Macro structure of spot welded zone for A6061 after the cross tensile test with the change of welding current

\subsection{Observation of Fracture Surface of Specimens Obtained after Cross-tensile Test}

Figure 13 shows SEM images of the fracture surface of the spot-welded zone of aluminum alloy obtained after the cross-tensile test. The crack propagation area in the HAZ has a flat and fragile fracture surface, indicating that the cracks generated in the cross-tensile test propagate along microfissures and in the eutectic melting area. In contrast, the forced fracture has a ductile surface with dimples. 


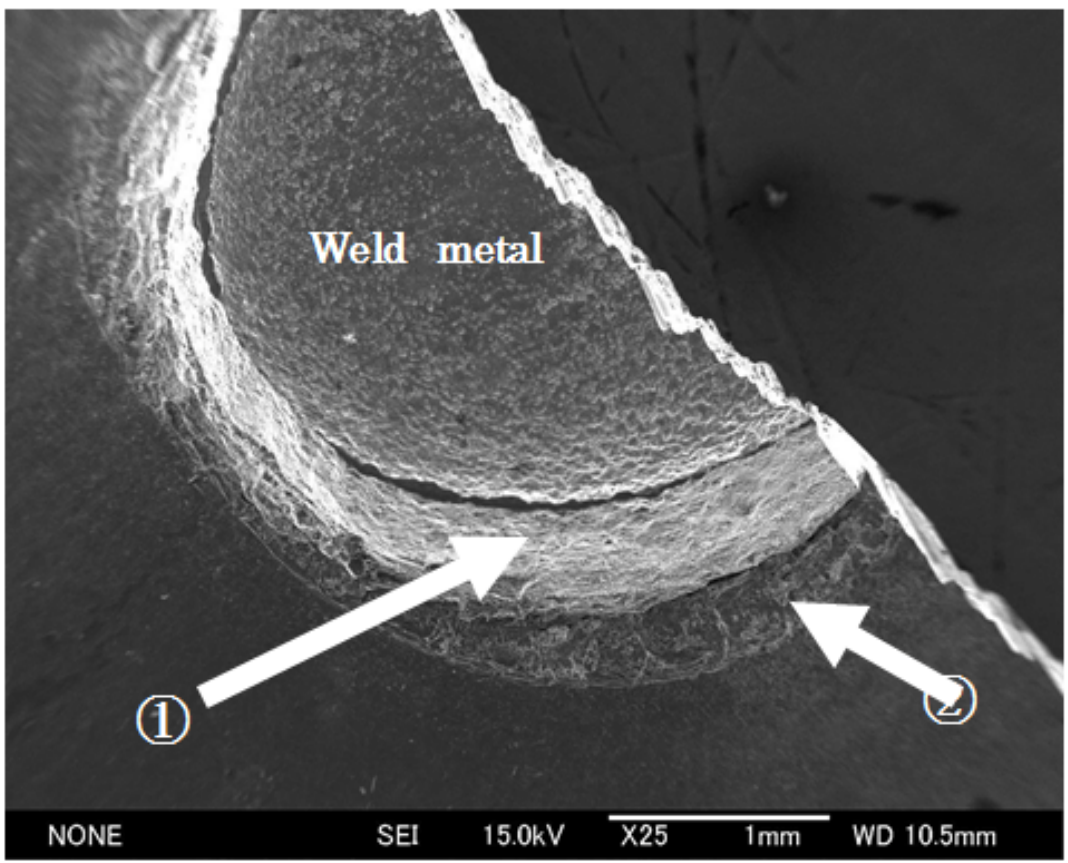

\section{(1)Corona bond}

\section{(2)Heat affectedzone}

Appearance of welded zone

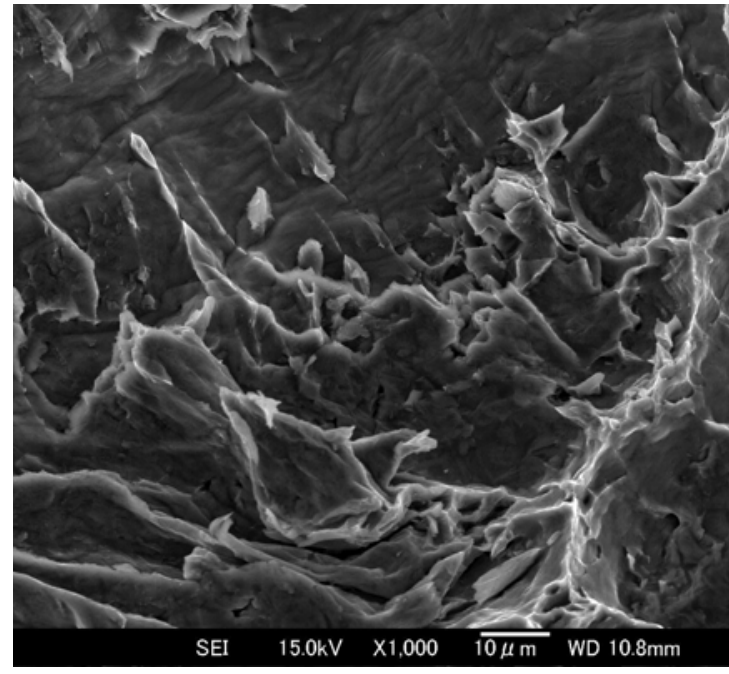

Position (1)

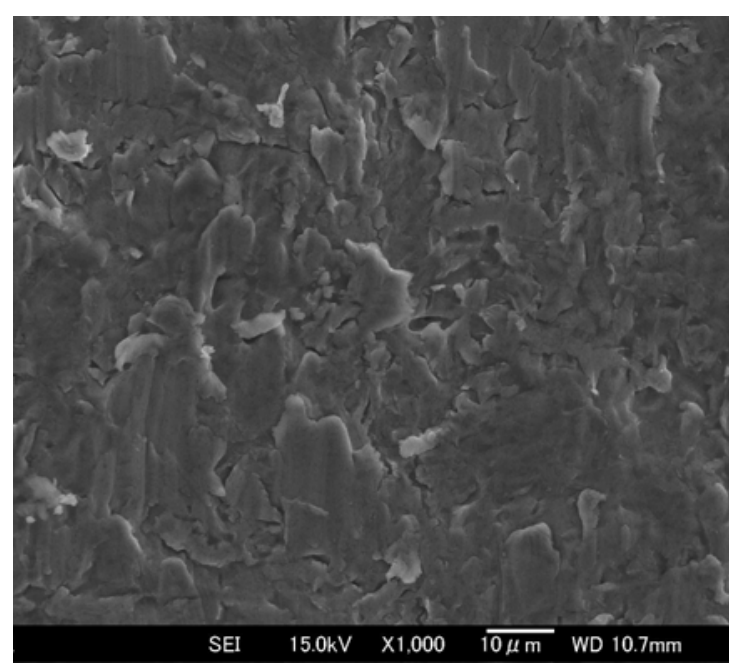

Position (2)

Figure 13. SEM structure of fracture surface for A6061 after cross tensile test 


\subsection{Comparison of Tensile Fractures of Spot-welded Zones of Aluminum Alloy and Mild Steel}

Cross-tensile testing of a spot-welded zone of mild steel was carried out to compare the results with those of aluminum alloy. Figure 14 shows the relationship between welding current and the maximum tensile load of the spot-welded zone of mild steel.

The maximum tensile load of the spot-welded zone of aluminum alloy becomes almost constant at a certain welding current or higher. However, the maximum tensile load of the spot-welded zone of mild steel tends to increase gradually with increasing welding current even under high current. In the spot-welded zone of mild steel, severe sputtering was observed at a welding current of $10 \mathrm{kA}$ or higher, unlike the case of aluminum alloy. Figure 15 shows typical macrostructures of the spot-welded zone of mild steel obtained after the cross-tensile test.

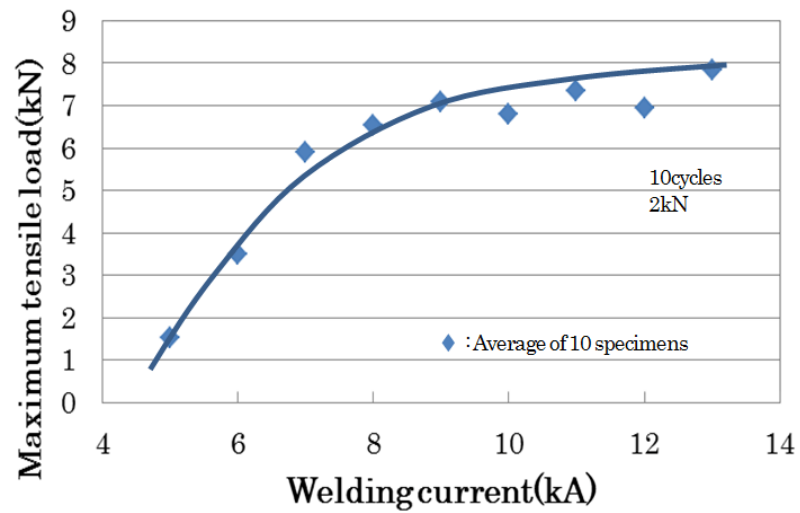

Figure 14. Relation between welding current and maximum tensile load in cross tensile test of mild steel

Under any welding current, the structure inside the nugget becomes coarse. At a welding current of $5.8 \mathrm{kA}$, part of the fracture path passes through the nugget. At welding currents of 8.8 and $12.8 \mathrm{kA}$, fracture is generated in the base metal. No microfissures were observed in the spot-welded zone of mild steel, unlike the case of HAZs in the spot-welded zone of aluminum alloy.

For the spot-welded zone of aluminum alloy, the maximum tensile load becomes almost constant at a welding current of $17 \mathrm{kA}$ or higher, as shown in Fig. 10. As is obvious from the relationship between welding current and nugget area (Fig. 4), the nugget area increases with increasing welding current even under the welding current of $17 \mathrm{kA}$ or higher. Namely, nuggets continue to grow with increasing welding current in the spot-welded zone of aluminum alloy; however, the maximum tensile load becomes almost constant at a certain welding current or higher, unlike the case of the spot-welded zone of mild steel. The comparison of the spot-welded zones of aluminum alloy and mild steel reveals that the trend of the maximum tensile load and the fracture state are different between the two. Therefore, the maximum tensile load of the spot-welded zone of aluminum alloy is considered to be almost constant at a certain welding current or higher because of the factors different from those for the spot-welded zone of mild steel.

\section{Discussion}

\subsection{Relationship between Welding Current and Tensile Fracture State}

The microstructural observation of the cross sections of the spot-welded zones of aluminum alloy and mild steel revealed that there are several fracture states. The fracture states can be classified into three modes, as shown in Fig. 16. For fracture mode I, cracks propagate inside the nugget to result in fracture because the nugget is insufficiently formed or large defects exist in the nugget. For fracture mode II, cracks propagate at the boundary of the nugget or in the HAZ, leading to a fracture. Fracture mode III is generally called tier fracture and cracks propagate in the base metal, leading to a fracture. Tables 6 and 7 summarize the fracture modes of the spot-welded zones of aluminum alloy and mild steel obtained at different welding currents, respectively.

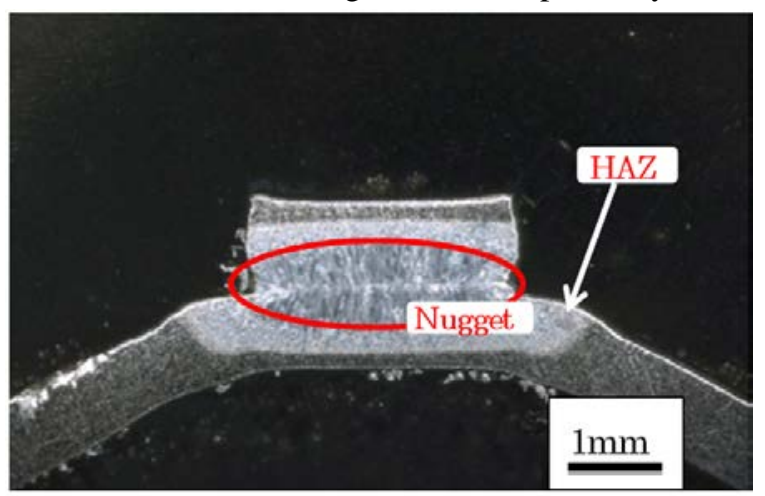

(a) Welding current : 5.8kA

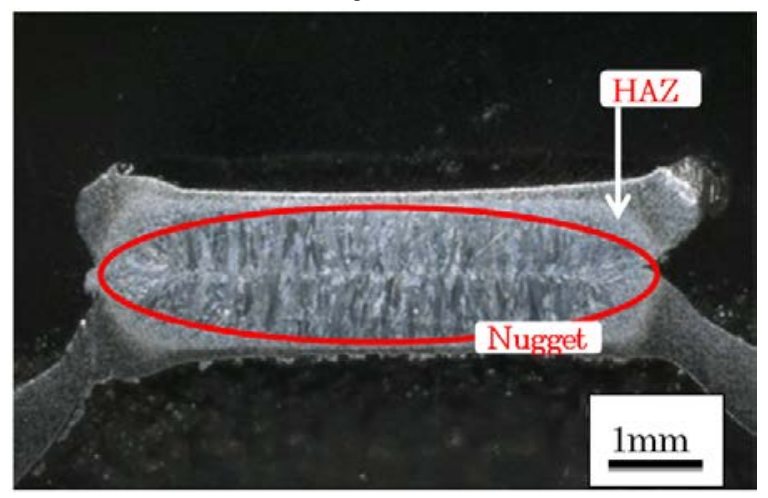

(b) Welding current : $8.8 \mathrm{kA}$

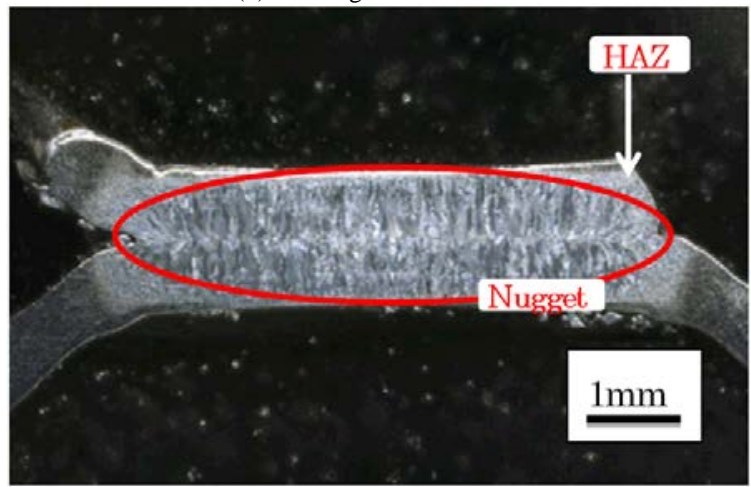

(c) Welding current : $12.8 \mathrm{kA}$

Figure 15. Macro structure of spot welded zone for mild steel after cross tensile test 
The fracture mode of the spot-welded zone of mild steel was fracture mode I at a low welding current of $4.8 \mathrm{kA}$ and a mixture of fracture modes I and III at a welding current of 5.8 $\mathrm{kA}$. At welding currents higher than $5.8 \mathrm{kA}$, it was fracture mode III. Fracture mode II was not observed under any welding current.

The fracture mode of the spot-welded zone of aluminum alloy was fracture mode I at low welding currents and a mixture of fracture modes I and II at welding currents of 18
$19 \mathrm{kA}$. At welding currents of $20 \mathrm{kA}$ or higher, it was fracture mode II. In the spot-welded zone with fracture mode II, fracture was generated in the HAZ; thus, the tensile strength of the spot-welded zone was not affected by the nugget. The main reason behind the almost constant maximum tensile load of the spot-welded zone of aluminum alloy at welding currents of $18 \mathrm{kA}$ or higher is considered to be fracture mode II. Fracture mode III was not observed at any welding current.

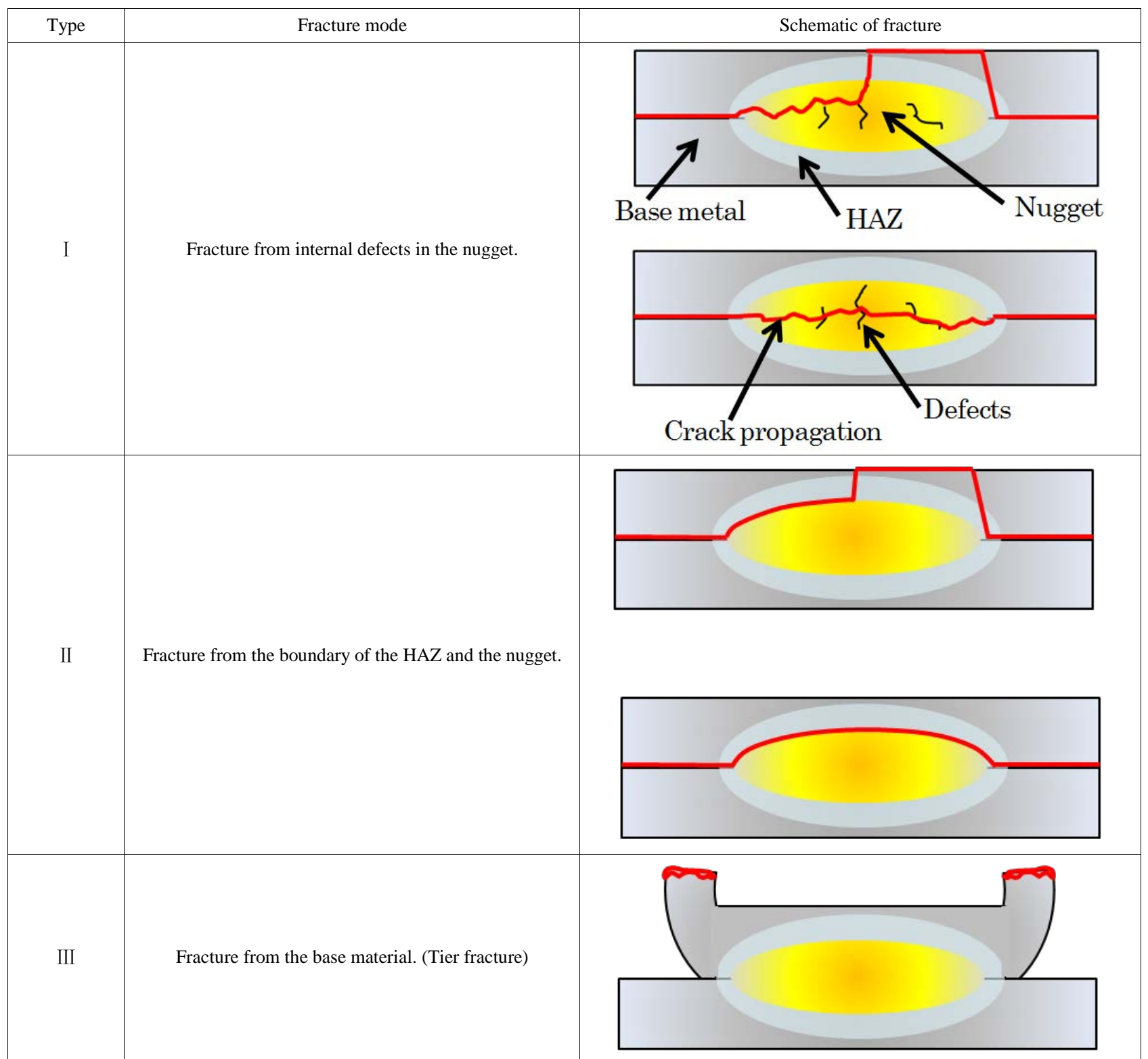

Figure 16. Classification of fracture mode of the welded zone A6061 and mild steel after cross tensile test test tensile test of mild steel 


\subsection{Change in Microfissures in $\mathrm{HAZ}$ with Increasing Welding Current}

From the microstructural observation of the cross section of the spot-welded zone, microfissures and eutectic melting areas were confirmed to coexist in the HAZ of aluminum alloy. With increasing welding current, the fracture path shifted from the nugget area to the HAZ. Because of the above findings, microfissures are considered to affect the change in the fracture mode. The change in microfissures in the HAZ with increasing welding current was examined. That is, one part $\left(0.0133 \mathrm{~mm}^{2}\right)$ was extracted from a microimage of the cross section to measure the lengths of microfissures and calculate the sum of the lengths (total length). The total length was calculated for ten different extracted parts to obtain the average of the total length under each condition. ImageJ was used for the measurement. Figure 17 shows the relationship between welding current and the total length of typical microfissures in the HAZ. As shown in Fig. 17, the total length of microfissures increases with increasing welding current. In addition, the number of microfissures increases with increasing welding current.

Table 6. Change in the fracture mode of A6061 by the welding current

\begin{tabular}{|c|c|c|c|c|c|c|c|}
\hline $\begin{array}{c}\text { Welding current } \\
\text { (kA) }\end{array}$ & 15 & 16 & 17 & 18,19 & 20 & $\sim$ & 23 \\
\hline Fracture mode & I & I & I & I , II & II & II & II \\
\hline
\end{tabular}

Table 7. Change in the fracture mode of mild steel by the welding current

\begin{tabular}{|c|c|c|c|c|c|}
\hline Welding current $(\mathrm{kA})$ & 5 & 6 & 7 & $\sim$ & 13 \\
\hline Fracture mode & I & I ,III & III & III & III \\
\hline
\end{tabular}

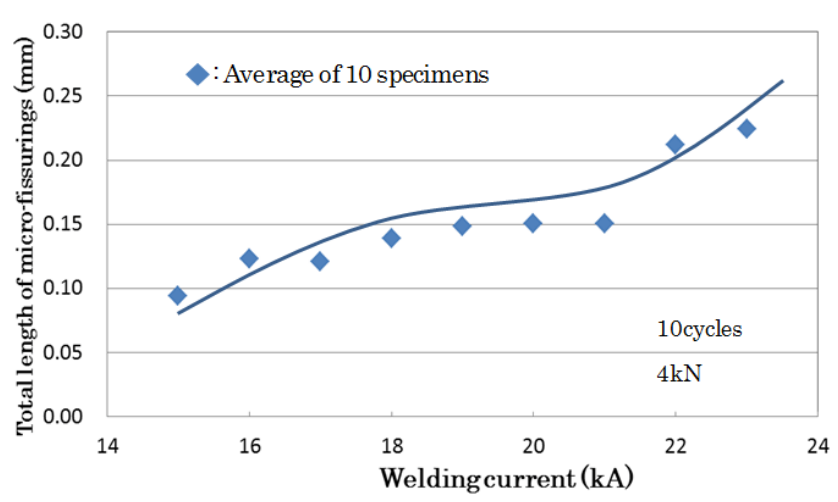

Figure 17. Relation between the welding current and the HAZ micro-fissuring of A6061

\subsection{Difference in Tensile Fracture Mechanism between Spot-welded Zones of Aluminum Alloy and Mild Steel}

Most of the fractures in the spot welded zone of mild steel were tier fractures (fracture mode III). In contrast, the number of microfissures in the HAZ increases with increasing welding current in the spot welded zone of aluminum alloy; hence, cracks generated during the cross-tensile test are considered to propagate along the boundary between the nugget and the HAZ or microfissures in the HAZ or in eutectic melting areas, even when the nugget area increases, which finally leads to fracture. Fig.18 shows the tensile strength (Maximum tensile load / nugget area) of the spot-welded zone of aluminum alloy. The tensile strength tended to decrease with increasing welding current. The results of SEM observation (Fig.13) also support that cracks generated during the cross-tensile test propagate along microfissures. The sharp-shaped non-junctions, as shown in Fig. 19, are observed at the end of the corona bond of the spot-welded zone, which is considered to serve as the starting point of fracture.

From the above findings, cracks generated at the end of the corona bond of the spot-welded zone can serve as the starting point of fracture and the increases in the numbers of the cracks and microfissures in the HAZ are considered to be the main cause behind the decrease in the strength of the spot-welded zone of aluminum alloy. During the cross-tensile test, cracks propagating in the HAZ lead to fracture. One of the reasons behind this is the softening of the HAZ, as shown in Fig. 20, owing to the heat generated during spot welding, because aluminum alloy A6061 is heat-treated. ${ }^{11)}$

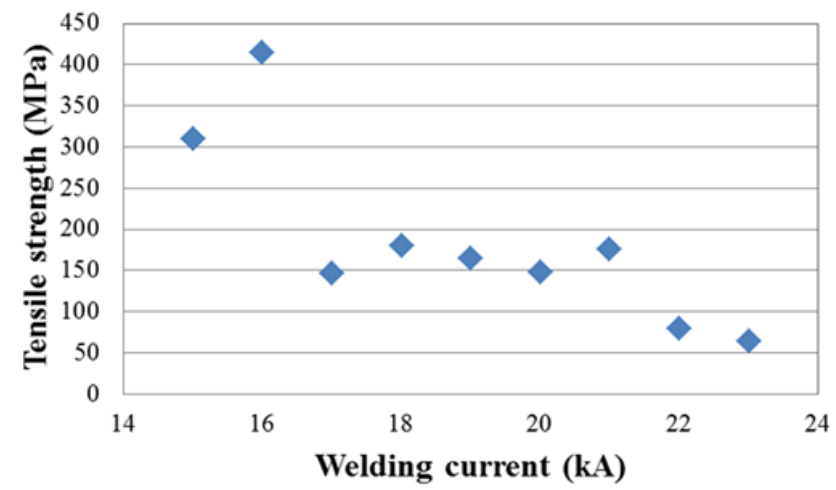

Figure 18. Relation between welding current and tensile strength(maximum tensile load / nugget area) in cross tensile test of A6061

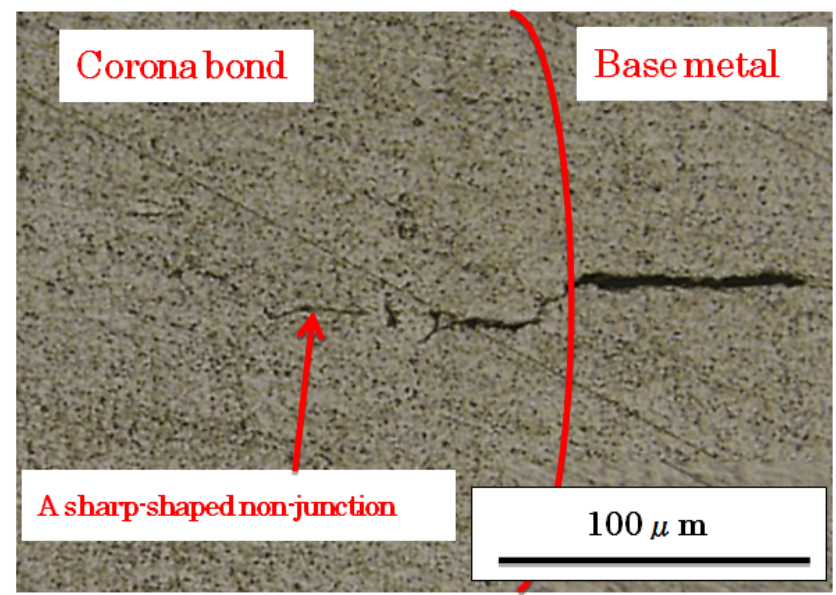

Welding current : 22kA

Figure 19. Sharp-shaped non-junction observed near the corona bond of spot welded zone for A6061 


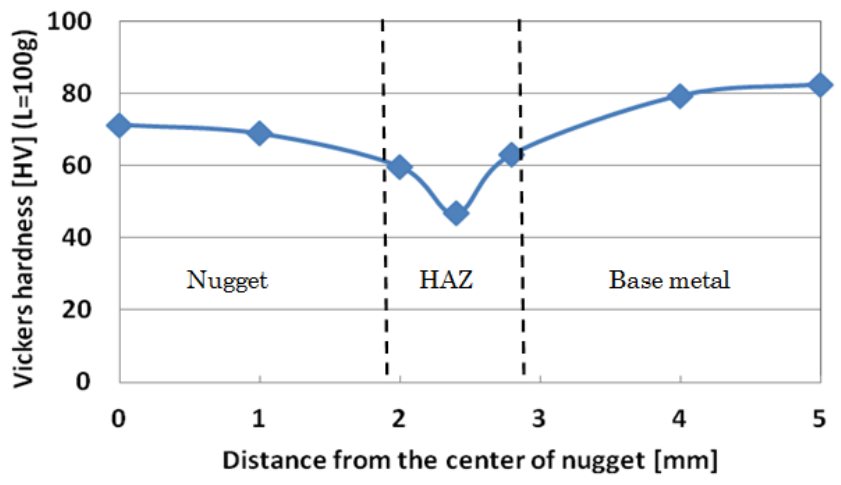

Figure 20. Vickers hardness distribution in spot welded zone for A6061

\section{Conclusions}

The growth of nuggets under different welding conditions, the generation of welding defects, and the effect of microstructure on the tensile load at the spot-welded zone were examined in spot-welded zones of aluminum alloy A6061 obtained under different welding conditions. We reached the following conclusions.

(1) Relationship between welding conditions and nugget area

The nugget area of aluminum alloy increases with increasing welding current. With increasing electrode force, the nugget area decreases. The nugget area almost changes with increasing welding time.

(2) Trend of fracture mode of spot-welded zone with increasing welding current

When the welding current is small, fracture starts from inside the nugget of the spot-welded zone of aluminum alloy. At welding currents of $17 \mathrm{kA}$ or higher, fracture starts from the HAZ.

(3) Microfissures in HAZ

Microfissures were observed in the HAZ of the spot-welded zone of aluminum alloy. The number of microfissures increases with increasing welding current.

(4) Mechanism behind fracture of spot-welded zone of aluminum alloy during cross-tensile test

For the spot-welded zone of mild steel, fracture starts from the base metal during cross-tensile test. With increasing welding current, tensile load increases.

In contrast, for the spot-welded zone of aluminum alloy, cracks generated during the cross-tensile test are considered to propagate along microfissures in the HAZ, which leads to fracture. Therefore, tensile load becomes almost constant at welding currents of $17 \mathrm{kA}$ or higher even when the nugget area increases with increasing welding current. It is also considered that sharp-shaped non-junctions existing at the end of the corona bond of the spot-welded zone can serve as the starting points of fracture.

\section{REFERENCES}

[1] T. Sakurai: Aluminum alloy sheet trends for automotive body panels, Kobe Steel Engineering Reports, Vol. 57, No. 2, (2007), 45-50.

[2] Y. Abe, K. Taromaru, T. Kato, and K. Mori: Strength characteristics and improvement of mechanically clinched joint in aluminum alloy sheets -comparison with self-pierce-riveted and resistance spot welded joints-, Journal of the Japan Society for Technology of Plasticity, Vol. 52, No. 610, (2011-11), 59-63.

[3] S. Oomachi, M. Nomoto, and K. Katoh: Mechanical properties of 6061 aluminum alloy/SPCC steel dissimilar butt joint by friction stir welding, Proceedings of 44th meeting of College of Industrial Technology, Nihon University (2011), 35-38.

[4] T. Sakiyama, G. Murayama, Y. Naito, K. Saita, Y. Miyazaki, H. Oikawa, and T. Nose: Dissimilar metal joining technologies for steel sheet and aluminum alloy sheet in auto body, Nippon Steel and Sumitomo Metal Technical Report, No. 392, (2012), 91-98.

[5] K. Matsuyama: New concept for spot welding of aluminum alloys, Symposium of joining technology of lightweight structure, Technology for joining aluminum alloy sheet and aluminum casting, (1996), 79-103.

[6] Y. Imamura and S. Sasabe: Resistance spot weld quality of Al-Mg alloy sheet, Quarterly Journal of the Japan Welding Society, Vol. 13, No. 1, (1995), 54-64.

[7] J. Takagi, N. Mori, and M. Fujimori: Fatigue strength of spot-welded joints of aluminum alloy sheets with solidification cracking nugget and its improvement, R\&D Review of Toyota CRDL, Vol. 34, No. 1, (1999), 41-47.

[8] T. Fukui and Y. Sugiyama: Micro-fissuring in heat-affected zone of aluminum alloy welds, Journal of the Japan Welding Society, Vol. 40, No. 9, (1971), 32-38.

[9] T. Fukui: Eutectic melting and micro-fissures in welded zone of aluminum alloy, Journal of the Japan Welding Society, Vol. 38, No. 6, (1969), 20-29.

[10] T. Nakamura and M. Hamazaki: Some studies of nugget formation phenomena on spot welding (Report 3), Journal of the Japan Welding Society, Vol. 37, No. 3, (1968), 49-57.

[11] R. Kawanishi: The effect of heat treatment on aluminum alloy for electric conductive use, Hitachi Review, Vol. 41, No. 5, (1959), 77-83. 